\title{
Movement Disability: Situations and Factors Influencing Access to Health Services in the Northeast of Thailand
}

\section{Wongkongdech A, ${ }^{1}$ Laohasiriwong $\mathrm{W}^{1}$}

${ }^{1}$ Faculty of Public Health

Research and Training Center for Enhancing Quality of Life of Working-Age People

Khon Kaen University

123 Moo 16 Mittapap Road, Nai-Mueang, Mueang District, Khon Kaen 40002, Thailand

\section{Corresponding Author}

Wongsa Laohasiriwong

Faculty of Public Health

Research and Training Center for Enhancing Quality of Life of Working-Age People

Khon Kaen University

123 Moo 16 Mittapap Road, Nai-Mueang, Mueang District, Khon Kaen 40002, Thailand

E-mail: drwongsa@gmail.com

\section{Citation}

Wongkongdech A, Laohasiriwong W. Movement Disability: Situations and Factors Influencing Access to Health Services in the Northeast of Thailand. Kathmandu Univ Med J 2014;47(3):168-74.

\begin{abstract}
Background

Persons with movement disability (PWMDs) are the biggest group of persons with disabilities (PWDs) with needs helps especially on health. There has been no evident to show health services accessibility situation of PWMDs in the Northeast of Thailand, the biggest region.
\end{abstract}

\section{Objective}

This study aimed to explore the current situation of accessibility to health services among PWMDs, and factors influencing such access.

\section{Method}

This cross-sectional study used a multistage stratified random sampling to select 462 subjects from the national registered PWMDs poll to response to a structured questionnaire. This study complies with the principles of the Declaration of Helsinki and was approved by the Khon Kaen University Ethics Committee for Human Research prior to the data collection.

\section{Result}

We found that most of PWMDs (66\%) had overall health service accessibility at medium level. Factors influencing the access to health services were living in rural area (adj. mean diff. $=-24.01 ; 95 \% \mathrm{Cl}:-45.88$ to-2.31; $\mathrm{p}$-value $=0.032$ ), high income (adj. mean diff. $=0.002 ; 95 \% \mathrm{Cl}: 0.001$ to $0.005 ; \mathrm{p}$-value $=0.044$ ), and having offspring or spouse as care givers (adj. mean diff. $=40.44 ; 95 \% \mathrm{Cl}$ : 7.69 to $73.19 ; \mathrm{p}$-value $=0.044$; and adj. mean diff. $=48.99 ; 95 \% \mathrm{Cl}: 15.01-82.98 ; \mathrm{p}$-value=0.016, respectively). PWMDs who lived in rural areas had better access to health services especially to the subdistrict health promoting hospital than those in the urban area.

\section{Conclusion}

Accessibly to health services of PWMDs still limited. Income, care givers and residential areas had influences on their access.

\section{KEY WORDS}

Domain of accessibility, health service, movement disability 


\section{INTRODUCTION}

In 2012, there were 1.4 million PWDs in Thailand, accounted for $2.1 \%$ of all Thai people (68 millions). The most common type of disability was movement disable (PWMDs) accounted for 0.6 million people (0.9\%) of Thai PWDs, of which 0.2 million, or $42.6 \%$ were in the Northeast region which considered the largest number of persons with movement disability (PWMDs) in the country. ${ }^{1}$

A study in a Northeast Province, Khon Kaen, in 2005 indicated that $58.62 \%$ of the participants had mobility impairments with poverty, insufficient income and unemployment. Other common problems were lack of food, utilities, and aiding tools. ${ }^{2}$ Most of the disabled received health promotion services at home, $50.5 \%$ had not received any rehabilitation services. The movement disables lost body functions permanently; therefore they were more likely to suffer in daily life. ${ }^{3}$

The Disabled Persons Promotion and Development Life Quality Act issued in 2007 gives rights to PWDs, the disabled are protected and support in education, employment, rehabilitation, health, information and technology, building code, transportation, poverty alleviation, and social security/social welfare. ${ }^{4}$ The needs of PWMDs should be better response thereafter.

PWMDs literatures usually focus on certain aspects/ dimensions of the access only. Therefore, this study applied the five dimensions of the access to health services as suggested by Penchansky and Thomas (1981) namely availability, accessibility, accommodation, affordability, acceptability to assess the level accessibility to health services, ${ }^{5}$ which included health promotion, disease prevention, curative and rehabilitation, to explore what are the situations and factors associated with accessibilities to different types of health services of PWMDs in the Northeast of Thailand.

\section{METHODS}

This cross-sectional study was conducted to explore the current situation of PWMDs in the Northeast of Thailand: their access to health services, together with examining factors affecting the access. The sample of 462 PWMDs was drawn, with a multistage stratified sampling technique, from the total population of 194,011 movement disabled who have registered with the Ministry of Social Development and Human Security in $2012 .^{6}$

The multistage stratified sampling was carried out by dividing the 20 Northeastern provinces into two groups - with and without regional hospitals: as the regional hospitals are more superior to the general hospitals, in terms of expertise, medical equipment, and health care services for the disabled, from where PWMDs could get better service and at the same time the regional hospitals could provide necessary supports to enhance the quality of the health service system of the general hospitals in their provinces - then, by the same proportion, randomly drew two provinces from the group with regional hospitals and another four provinces from the group without regional hospitals (or only with general hospitals). That made the total of six provinces to complete the first stage. Followed then by randomly selected two districts from each of the six provinces, thus there made the total of 12 districts. PWMDs in these districts were finally drawn by simple random technique to the estimated sample size (462 subjects), derived from the formula for multiple regression analysis, ${ }^{7}$ and adjusted to the design effect of $1.5 .^{8}$

Data collection process was conducted by approaching the relevant parties both authorities and respondents involved in the study to obtain relevant information and approval to conduct the research in the areas, collecting primary and secondary data on general characteristics of PWMDs and their context on related health determinants, and collecting data regarding the access to health care services. All analyses were performed using STATA ${ }^{\circledR}$ (vers 13; College Station, TX, USA: Stata Corp).

Descriptive statistics were employed to describe the characteristics of persons with disabilities; namely demographic, geography of areas, socio-cultural, physical environmental, health care service system, plan, and policy at baseline. The multiple regress analysis, with the mean difference of $95 \% \mathrm{Cl}$, was deployed as inferential statistic to investigate the influences of factors on the access to health care services in five dimensions: availability, accessibility, accommodation, affordability and acceptability.

\section{Ethical considerations}

This study complies with the principles of the Declaration of Helsinki and was approved by the Khon Kaen University Ethics Committee for Human Research prior to the data collection (Ref. No HE552349; 2013 Feb 2). The author and the colleague respected and protected the disabled rights. We took the disabled rights into consideration while designing and conducting the entire research process.

\section{RESULTS}

\section{Demographic data of subjects}

The results (Table 1 ) showed that majority of the subjects were male, married, and had an average age of 60 years old. About $70 \%$ lived in the rural area, with the family size of four people and less (57\%), and almost all of them stayed with their spouse and family. Approximately $80 \%$ of the respondents finished only primary school education. Most of them were unemployed. However, some reported that they had monthly income fewer than THB 1,000 from various sources such as welfare, compensation from social security, whereas other reported to have receiving support directly from the family.

Regarding the caregivers, the spouse and offspring play 
Table 1. Characteristics of subjects.

\begin{tabular}{|c|c|c|}
\hline Characteristics & $\mathbf{n}$ & $\%$ \\
\hline \multicolumn{3}{|l|}{ Resident Area } \\
\hline Urban & 138 & 29.87 \\
\hline Rural & 324 & 70.13 \\
\hline Gender: Male & 253 & 54.76 \\
\hline \multicolumn{3}{|l|}{ Age (years) } \\
\hline$\leq 40-59$ & 224 & 48.85 \\
\hline$\geq 60-79$ & 238 & 51.15 \\
\hline Marital status: Married & 236 & 51.08 \\
\hline Education:Finished primary school & 390 & 84.42 \\
\hline Monthly Income: $<1,000$ THB & 408 & 88.31 \\
\hline Live with spouse and family & 433 & 93.72 \\
\hline \multicolumn{3}{|l|}{ Caregiver in everyday life } \\
\hline Spouse & 140 & 30.30 \\
\hline Offspring & 126 & 27.27 \\
\hline Self care & 78 & 16.88 \\
\hline Parents & 74 & 16.02 \\
\hline Relatives & 37 & 8.01 \\
\hline Others & 7 & 1.52 \\
\hline \multicolumn{3}{|l|}{ Hospital } \\
\hline Regional Hospital & 160 & 34.6 \\
\hline General Hospital & 302 & 65.4 \\
\hline \multicolumn{3}{|l|}{ Distance to health care unit } \\
\hline $1-5$ km \& shorter & 401 & 86.80 \\
\hline 6 - $10 \mathrm{~km} \&$ longer & 61 & 13.2 \\
\hline \multicolumn{3}{|l|}{ Transportation } \\
\hline Walking & 152 & 32.90 \\
\hline Wheelchairs & 265 & 57.36 \\
\hline Bicycle & 40 & 8.66 \\
\hline
\end{tabular}

the big role in taking care of PWMDs in everyday life (30\% and $27 \%$, respectively). During crisis and ailment, while the disabled could not take care of themselves, the spouse and offspring were reported to get more involved in caring the disabled (36\% and $30 \%$, respectively). It is noteworthy that the parents also lend the hand to those in needs both during the crisis and in everyday life (approximately 16.5\% in both cases). Even though there are caregivers, when evaluating the daily living, based on Barthel Index, ${ }^{9,10}$ four tenth of the respondents suggested that they were totally independent on daily living, whereas $30 \%$ of them need only minimal attention from their caregivers.

The highest proportion of disability among the PWMDs was hemiparesis (40.26\%). About nine tenths of the movement disabled suffered from single disability. The median time of being disabled was 10 years. Majority of the PWMDs did not have any underlining disease or illness (54.33\%). The top three underlining diseases were hypertension (23.59\%), DM (18.62\%), and cardiovascular disease (7.36\%).

From the self-assessment health status, the mean of health status score was 6.45 (SD=2.31), however, it is noteworthy
Daily living evaluation

\begin{tabular}{|rcc|}
\hline Totally dependence & 34 & 7.36 \\
\hline Almost dependence & 49 & 10.61 \\
\hline Moderately sever dependence & 52 & 11.26 \\
\hline Mildly sever dependence & 132 & 28.57 \\
\hline Totally independence & 195 & 42.21 \\
\hline
\end{tabular}

Type of Movement Disability

\begin{tabular}{|c|c|c|}
\hline Hemi paresis & 186 & 40.26 \\
\hline Amputated leg & 61 & 13.20 \\
\hline Atrophied leg & 51 & 11.04 \\
\hline Paraplegia & 40 & 8.66 \\
\hline Other movement disability & 31 & 6.71 \\
\hline Paresis & 27 & 5.84 \\
\hline Abnormal vertebral column & 25 & 5.41 \\
\hline Paraparesis & 21 & 4.55 \\
\hline Paralysis & 9 & 1.95 \\
\hline Hemiplegia & 6 & 1.30 \\
\hline Amputated arm & 5 & 1.08 \\
\hline Multiple disability & 47 & 10.17 \\
\hline \multicolumn{3}{|l|}{ Disabilities types } \\
\hline Only movement disability & 413 & 89.39 \\
\hline Multiple Disabilities & 49 & 10.61 \\
\hline \multicolumn{3}{|l|}{ Underlying Diseases / illness } \\
\hline Without diseases/ illness & 252 & 54.55 \\
\hline With Diseases/ illness & 210 & 45.45 \\
\hline Health status: Mean (SD) & 148.23 & $(112.45)$ \\
\hline \multicolumn{3}{|l|}{ Health knowledge level } \\
\hline Low & 51 & 11.04 \\
\hline Moderate & 71 & 15.37 \\
\hline High & 340 & 73.59 \\
\hline
\end{tabular}

that about half indicated lower than six scores on their health. The policies of which most of the disable knew were welfare allowances for the disabled, support of movementaided equipment, and support on vocational training for the disabled ( $82.25 \%, 55.19 \%$ and $41.77 \%$, respectively).

With regards to the rights of the disabled, many of the respondents were not aware of their rights (64.07\%). The rights of which PWMDs knew were the right to access to disability benefit, welfare allowances; the right to receive rehabilitation services by the medical staff and treatment expenses, including equipment costs; the right to take advantage of the facilities and other assistance from the state; and the right of not to be discrimination because of persons' disabilities (29\%, 18.61\%, $17.32 \%$ and $12.34 \%$, respectively).

During the past one year, in sub-district health promoting hospital, PWMDs have participated in the disease services (41.77\%), curative services (38.61\%), health promotion (29.22\%), and rehabilitation (16.88\%). Community hospital, on the other hand, PWMDs received curative care $27.92 \%$, disease prevention $17.32 \%$, health promotion 
$14.5 \%$, and rehabilitation $8.87 \%$, whereas $13.42 \%$ and $11.69 \%$ of PWMDs received curative services from general and regional hospital respectively. Only $2.06 \%$ and $2.36 \%$ of the PWMDs got rehabilitation services from general and regional hospitals.

\section{The access to health service}

Concerning the access to health services, the most common transportation means to reach the health care facility of the PWMDs are wheelchairs (57.36\%) and walking (32.90\%). When investigating the access to health care services, approximately seven tenth of the respondents ranked the overall scale of the access at medium level, while the rest gave their marks almost equally between the high and low levels. The similar result applied to all of the five domains of the access - availability, accessibility, affordability, acceptability, and accommodation. While the high and low levels on all domains seem to be equally distributed, however, there is a noticeable exception on the affordability domain - the respondents rank this domain on the lower side of the scale, as it seems that some subjects feel that they could not afford the access to health care service.

\section{Factors influencing the access to health care services}

From Table 2, when comparing the mean score level of the access to health services between PWMDs who live in two different areas, concerning regional hospital, it is found that the subjects in provinces with regional hospital had a lower access mean score (140.51 \pm 103.28$)$, whereas the mean score of those who live in the provinces with no regional hospital (there was a general hospital) was at $151.76 \pm 116.25$, with a mean difference of 11.25 (95\% Cl of -10.25 to 32.76$)$.

When observing each domain of access, the mean scores of all domains of the PWMDs in the provinces with regional hospitals are still lower than those in the provinces with only general hospitals. The items, which had the highest mean difference between the two settings, were preparation for assistant device (mean difference=1.23), convenience of transportation to health service facilities (mean difference $=0.37$ ) and ability to accommodate the expense (mean difference=1.06).

Table 2. Mean difference of factors associated with access to health services among persons with movement disability compared between main types of hospital ( $N=462)$

\begin{tabular}{|c|c|c|c|c|c|c|}
\hline \multirow[t]{3}{*}{ Access to health services } & \multicolumn{4}{|c|}{ Province group } & \multirow{3}{*}{$\begin{array}{c}\text { Mean } \\
\text { diff }\end{array}$} & \multirow{3}{*}{$\begin{array}{c}95 \% \mathrm{Cl} \\
\text { mean diff }\end{array}$} \\
\hline & \multicolumn{2}{|c|}{$\begin{array}{l}\text { With regional hospital } \\
\qquad(n=160)\end{array}$} & \multicolumn{2}{|c|}{$\begin{array}{l}\text { With general hospital } \\
\qquad(n=302)\end{array}$} & & \\
\hline & Mean & SD & Mean & SD & & \\
\hline Adequacy of health personal & 9.71 & 7.26 & 10.30 & 8.24 & 0.59 & -0.92 to 2.11 \\
\hline Adequacy of assisting device & 9.14 & 7.04 & 10.37 & 8.41 & 1.23 & -.29 to 2.76 \\
\hline Response to the needs & 9.51 & 7.10 & 10.29 & 8.31 & 0.78 & -.73 to 2.30 \\
\hline Availability for vehicle for transportation & 8.90 & 7.19 & 9.72 & 7.93 & 0.82 & -.65 to 2.29 \\
\hline Convenient of transportation & 10.30 & 8.68 & 10.67 & 8.41 & 0.37 & -1.2 to 2.01 \\
\hline Hospitality of health personal & 9.97 & 7.42 & 10.63 & 8.42 & 0.65 & -.89 to 2.21 \\
\hline Caring of health personnel & 9.88 & 7.36 & 10.29 & 8.25 & 0.41 & -1.11 to 1.94 \\
\hline Waiting time & 9.07 & 6.84 & 9.19 & 7.26 & 0.11 & -1.25 to 1.48 \\
\hline Convenient of movement in the hospital & 9.47 & 7.04 & 10.53 & 9.65 & 1.06 & -.63 to 2.76 \\
\hline Adequacy of toilet for disable & 9.12 & 6.96 & 10.05 & 8.20 & 0.92 & -.56 to 2.42 \\
\hline Respect to disable right and dignity & 9.66 & 7.19 & 10.65 & 8.38 & 0.98 & -.54 to 2.52 \\
\hline Affordability for Expense & 7.96 & 6.05 & 9.03 & 6.95 & 1.06 & -.21 to 2.34 \\
\hline Value of money for the care received & 9.45 & 8.34 & 10.17 & 8.14 & 0.71 & -0.86 to 2.29 \\
\hline Appropriate to patient life style context & 9.35 & 6.95 & 10.29 & 8.17 & 0.84 & 0.81 to 0.87 \\
\hline Satisfaction & 8.96 & 6.23 & 9.51 & 7.50 & 0.55 & -.80 to 1.91 \\
\hline Total & 140.51 & 103.28 & 151.76 & 116.23 & 11.25 & -10.25 to 32.76 \\
\hline
\end{tabular}


The crude analysis (Table 3 ) identifies the factors that correlated with the access to health care services. Those factors are residential area, marital status, educational attainment, monthly income, living with offspring, living with spouse, distance from home to health care facility, and having chronic disease. The mentioned factors were then analyzed with the multiple regression model.

Table 3. Mean difference of factors associated with access to health services among persons with movement disability based on simple linear regression $(N=462)$

\begin{tabular}{|c|c|c|c|c|c|c|}
\hline Factor lists & $n$ & Mean & SD & $\begin{array}{l}\text { Mean } \\
\text { diff }\end{array}$ & $95 \% \mathrm{Cl}$ & $p$-value \\
\hline Hospital & & & & & & 0.285 \\
\hline $\begin{array}{l}\text { Regional } \\
\text { Hospital }\end{array}$ & 160 & 140.54 & 103.19 & 0 & & \\
\hline $\begin{array}{l}\text { General } \\
\text { Hospital }\end{array}$ & 302 & 152.31 & 117.03 & 11.77 & $\begin{array}{l}-9.83 \text { to } \\
33.38\end{array}$ & \\
\hline $\begin{array}{l}\text { Resident } \\
\text { Area }\end{array}$ & & & & & & 0.029 \\
\hline Urban & 138 & 162.30 & 99.06 & 0 & & \\
\hline Rural & 324 & 142.24 & 117.33 & -20.06 & $\begin{array}{l}2.35 \text { to } \\
-42.48\end{array}$ & \\
\hline Sex & & & & & & 0.557 \\
\hline Male & 253 & 145.44 & 113.24 & 0 & & \\
\hline Female & 209 & 151.62 & 111.68 & 6.18 & $\begin{array}{l}-14.49 \text { to } \\
26.85\end{array}$ & \\
\hline $\begin{array}{l}\text { Age of } \\
\text { PWMDs } \\
\text { (yrs) }\end{array}$ & & & & & & 0.293 \\
\hline$<20$ & 14 & 143.71 & 132.10 & 0 & & \\
\hline $20-39$ & 71 & 124.27 & 106.44 & -19.45 & $\begin{array}{l}-84.01 \text { to } \\
45.11\end{array}$ & \\
\hline $40-59$ & 139 & 145.29 & 109.32 & 1.58 & $\begin{array}{l}-60.32 \text { to } \\
63.48\end{array}$ & \\
\hline $60-79$ & 190 & 156.68 & 116.19 & 12.96 & $\begin{array}{l}-48.17 \text { to } \\
74.10\end{array}$ & \\
\hline$\geq 80$ & 48 & 160.08 & 107.85 & 16.37 & $\begin{array}{l}-50.68 \text { to } \\
83.43\end{array}$ & \\
\hline $\begin{array}{l}\text { Marital } \\
\text { status }\end{array}$ & & & & & & 0.001 \\
\hline $\begin{array}{r}\text { Single, } \\
\text { Widow, } \\
\text { Divorce, } \\
\text { Separate }\end{array}$ & 226 & 135.94 & 110.05 & 0 & & \\
\hline Married & 236 & 159.67 & 113.70 & 24.05 & $\begin{array}{l}3.58 \text { to } \\
44.52\end{array}$ & \\
\hline $\begin{array}{l}\text { Educa- } \\
\text { tional at- } \\
\text { tainment }\end{array}$ & & & & & & 0.005 \\
\hline Not study & 59 & 113.79 & 96.39 & 0 & & \\
\hline $\begin{array}{r}\text { Primary } \\
\text { school }\end{array}$ & 331 & 158.73 & 115.99 & 44.94 & $\begin{array}{l}14.01 \text { to } \\
75.87\end{array}$ & \\
\hline $\begin{array}{r}\text { Secondary } \\
\text { school \& } \\
\text { higher }\end{array}$ & 72 & 128.18 & 100.43 & 14.38 & $\begin{array}{l}-24.05 \text { to } \\
52.82\end{array}$ & \\
\hline
\end{tabular}

\begin{tabular}{|c|c|c|c|c|c|c|}
\hline $\begin{array}{l}\text { Monthly } \\
\text { income }\end{array}$ & 426 & 148.22 & 112.46 & 0.003 & $\begin{array}{l}-0.001 \text { to } \\
0.005\end{array}$ & 0.148 \\
\hline $\begin{array}{l}\text { Person } \\
\text { Who Live } \\
\text { with PW- } \\
\text { MDs }\end{array}$ & & & & & & 0.018 \\
\hline $\begin{array}{r}\text { PWMD is } \\
\text { alone }\end{array}$ & 22 & 118.45 & 99.58 & 0 & & \\
\hline Parents & 84 & 121.90 & 99.91 & 3.45 & $\begin{array}{l}-49.13 \text { to } \\
56.03\end{array}$ & \\
\hline $\begin{array}{r}\text { Spouse } \\
\text { and family }\end{array}$ & 356 & 156.29 & 114.97 & 37.83 & $\begin{array}{l}-10.40 \text { to } \\
86.07\end{array}$ & \\
\hline $\begin{array}{l}\text { Care giver } \\
\text { in everyday } \\
\text { life }\end{array}$ & & & & & & 0.001 \\
\hline Self care & 85 & 115.61 & 104.33 & 0 & & \\
\hline Parents & 74 & 116.53 & 97.74 & 0.92 & $\begin{array}{l}-33.55 \text { to } \\
35.38\end{array}$ & \\
\hline Offspring & 126 & 163.94 & 116.20 & 48.32 & $\begin{array}{l}17.89 \text { to } \\
78.76\end{array}$ & \\
\hline Relative & 37 & 147.27 & 100.48 & 31.65 & $\begin{array}{l}-11.04 \text { to } \\
74.35\end{array}$ & \\
\hline Spouse & 140 & 170.92 & 116.89 & 55.31 & $\begin{array}{l}25.49 \text { to } \\
85.12\end{array}$ & \\
\hline $\begin{array}{l}\text { Distance } \\
\text { from } \\
\text { home to } \\
\text { the main } \\
\text { health } \\
\text { care unit } \\
\text { registered } \\
\text { with the } \\
\text { NHSO }\end{array}$ & 462 & 148.23 & 3.17 & 2.13 & $\begin{array}{l}-1.11 \text { to } \\
5.38\end{array}$ & 0.196 \\
\hline $\begin{array}{l}\text { Disabilities } \\
\text { types }\end{array}$ & & & & & & 0.769 \\
\hline $\begin{array}{r}\text { Only } \\
\text { movement } \\
\text { disability }\end{array}$ & 413 & 148.76 & 111.49 & 0 & & \\
\hline $\begin{array}{r}\text { Multiple } \\
\text { Disabilities }\end{array}$ & 49 & 143.78 & 121.46 & 4.98 & $\begin{array}{l}-38.41 \text { to } \\
28.44\end{array}$ & \\
\hline $\begin{array}{l}\text { Underlying } \\
\text { Diseases / } \\
\text { illness }\end{array}$ & & & & & & $<0.001$ \\
\hline $\begin{array}{r}\text { Without } \\
\text { diseases/ } \\
\text { illness }\end{array}$ & 252 & 126.95 & 113.40 & 0 & & \\
\hline $\begin{array}{r}\text { With } \\
\text { Diseases/ } \\
\text { illness }\end{array}$ & 210 & 173.77 & 106.05 & 46.81 & $\begin{array}{l}26.59 \text { to } \\
67.04\end{array}$ & \\
\hline $\begin{array}{l}\text { Health } \\
\text { status }\end{array}$ & 462 & 148.23 & 112.45 & -0.66 & $\begin{array}{l}-5.11 \text { to } \\
3.78\end{array}$ & 0.768 \\
\hline $\begin{array}{l}\text { Health } \\
\text { knowledge } \\
\text { level }\end{array}$ & & & & & & 0.309 \\
\hline Low & 51 & 137.96 & 102.01 & 0 & & \\
\hline Moderate & 71 & 132.88 & 109.42 & -5.07 & $\begin{array}{l}-45.00 \text { to } \\
35.47\end{array}$ & \\
\hline High & 340 & 152.97 & 114.46 & 15.01 & $\begin{array}{l}-18.00 \text { to } \\
48.19\end{array}$ & \\
\hline
\end{tabular}


The final model from multivariable analysis (Table 4), analyzed with the Multiple Linear Regression equation, indicates that factors which have association with access to health care services among persons with movement disability in the Northeast of Thailand when control other covariate factors were residential area, monthly income, having offspring and spouses as caregivers in everyday life.

Table 4. Mean difference of factors associated with access to health services among persons with movement disability based on multiple linear regression ( $N=462$ ).

\begin{tabular}{|c|c|c|c|c|c|c|c|}
\hline \multirow{2}{*}{$\begin{array}{l}\text { Charac- } \\
\text { teristics }\end{array}$} & \multirow[t]{2}{*}{$n$} & \multirow[t]{2}{*}{ Mean } & \multirow[t]{2}{*}{ SD } & \multicolumn{3}{|c|}{ Mean diff } & \multirow{2}{*}{$\begin{array}{c}\mathrm{p}- \\
\text { value }\end{array}$} \\
\hline & & & & Crude & Adj & $95 \% \mathrm{Cl}$ & \\
\hline $\begin{array}{l}\text { Resident } \\
\text { Area }\end{array}$ & & & & & & & 0.032 \\
\hline Urban & 138 & 162.30 & 99.06 & 0.00 & 0.00 & & \\
\hline Rural & 324 & 142.24 & 117.33 & -20.06 & -24.01 & $\begin{array}{l}-45.88 \\
\text { to }-2.13\end{array}$ & \\
\hline $\begin{array}{l}\text { Monthly } \\
\text { income }\end{array}$ & 426 & 148.00 & 112.46 & 0.003 & 0.002 & $\begin{array}{l}0.001 \\
\text { to } \\
0.005\end{array}$ & 0.044 \\
\hline $\begin{array}{l}\text { Care- } \\
\text { giver in } \\
\text { daily life }\end{array}$ & & & & & & & 0.016 \\
\hline Self care & 85 & 115.61 & 104.33 & 0.00 & 0.00 & & \\
\hline Parents & 74 & 116.53 & 97.74 & 0.92 & -6.46 & $\begin{array}{l}-52.05 \\
\text { to } \\
39.11\end{array}$ & \\
\hline $\begin{array}{r}\text { Off } \\
\text { spring }\end{array}$ & 126 & 163.94 & 116.20 & 48.32 & 40.44 & $\begin{array}{l}7.69 \\
\text { to } 73.19\end{array}$ & \\
\hline Relatives & 37 & 147.27 & 100.48 & 31.65 & 22.80 & $\begin{array}{l}-22.24 \\
\text { to } \\
67.84\end{array}$ & \\
\hline Spouse & 140 & 170.92 & 116.89 & 55.31 & 48.99 & $\begin{array}{l}15.01 \\
\text { to } \\
82.98\end{array}$ & \\
\hline
\end{tabular}

\section{DISCUSSION}

Regarding the activity of daily living based on Barthel Index, the results suggest that $37.9 \%$ of the PWMDs were some degrees of dependency, which could be the physically, psychologically and financially burdens to the caregivers and other family members. Therefore, they needed support from relevant sectors such as the Ministry of Social Development and Human Security, Ministry of Public Health and local administration organization in accordance to the Law and rights of the PWDs. It is good that PWMDs were aware of their rights, especially the rights to receive the welfare allowance. However, the allowance was only 500 Baht per month, which might not be enough to ease up the burden, particularly if the disabled were fully dependent and/or poor. Besides, many of them were not aware of some their rights.

The rights of which PWMDs knew were the right to receive rehabilitation services by the medical staff and treatment expenses, including equipment costs; the right to take advantage of the facilities and other assistance from the state; and the right of not to be discriminated because they are persons with disabilities. It is crucial to make improvement on disseminating the information on the rights, so that they are known to the unaware ones, especially for the PWMDs who suffer from some degrees of disability which rehabilitation services are essential as well as the movement assisting equipment. The less the disabled are aware of their rights, the more likely they are neglected.

Some studies indicate that marital status is associated with the accessibility to equipment and informal care among the disabled. ${ }^{11,12}$ However, from our study, marital status did not show any statistically significant association with the access to health services. On the other hand, having spouse and offspring as caregiver in everyday life were found to have significantly positive influence on the access to health services. The finding suggests that when caregivers had strong tie relationships with PWMDs, they were more likely to care more on the PWMDs' well being.

PWMDs reported that they have participated in the disease prevention services, curative measures, health promotion scheme, and attend the rehabilitation services. This finding is similar to, but at the same time different from the previous study of Polkeng and Laohasiriwong (2009), which indicated that the fewest health services which PWMDs in Chaiyapum Province had was rehabilitation which is similar with this study. However, the health promotion was found to be the most utilized health service among PWMDs in Chaiyapum; whereas, in this study, the disease prevention services was the most common service used, followed by curative measures.

A quite number of the PWMDs had underlining diseases and disabilities which some of the medical providers might classify them as patients who needed secondary prevention (prevent the diseases), such as physical check up, immunization and curative care more than health promotion. Many PWMDs received health services from a sub-district health promoting hospital, coming in the second rank was a community hospital, of which PWMDs received curative care $(27.9 \%)$, disease prevention $17.3 \%$, health promotion (14.5\%) and rehabilitation (8.9\%).

The possible reason the disabled come to the sub-district health center the most is because they could not travel very far due to their movement disability. Another possible explanation is the sub-district health centers provide a better quality of care in the lower level of health care facility, and the PWMDs are their first priority. Regarding curative services, $13.4 \%$ and $11.7 \%$ of PWMDs received the services from general and regional hospital respectively. Almost the same $2 \%$ of the PWMDs got rehabilitation services from general and regional hospitals. It is quite certain that the tertiary level does not have any direct effect in providing the services to PWMDs.

Regarding health literacy in general, the disabled health literacy might not only reflected the poor access to some 
health information, but might also reflected the broader aspect of inadequate education (71.7\% finished primary education, $12.8 \%$ are illiterate). Lacking an opportunity for further/higher education which found in this study is similar to the previous findings, ${ }^{13,14}$ which indicated that disabled children were less likely than children without disabilities to start school and had lower rates of staying and being promoted in school. In our study most of the PWMDs occurred when they were in adulthood, it might not affect the educational attainment, however, employment was a problems since $81.39 \%$ was unemployed, of which $71.13 \%$ was unemployed due to their disabilities.

Many of the PWMDs have overall access to health services at medium level (66.0\%), which was generally lower than people without disabilities, who usually had larger proportion for high level of access to health services. The domain which turns out to be the lowest level was affordability domain, $72.3 \%$ at medium level and another $16.2 \%$ at the low level, whereas the majority of other domains were at the medium level, and then followed by high level. It could be explained by the fact that many of them had low income $(<1,000 \mathrm{THB} /$ month). Despite the free health services, they still had to pay for transportation, food of themselves and their caregivers. Moreover, the opportunity cost from the fact that the caregiver lost their income since they have to look after the PWMDs or took them to the hospital was also high and could hinder the access to the health services. This might be the underlying reason for lower accessibility to health service in the provinces with regional hospitals which were more urbanized, that end up with high expenditure and the PWMDs nor their family had any close/friendly relationships with health personnel.
Limitation of the study is that the study used the data of movement disabled who have registered with the Ministry of Social Development and Human Security in 2012 which are not included those who have not registered.

\section{CONCLUSION}

In summary, most of the PWMDs had poor access to health services especially the rehabilitation. Factors influencing the access to health services among PWMDs in the Northeast of Thailand are residential area, monthly income, having offspring and spouse as caregivers in everyday life. Those who lived in rural area were more convenient in traveling to the sub district health promoting hospital than those in the urban area. Those who had higher income were more likely to afford the access to health service. The strong tie relationships between caregivers and PWMDs contributed to the higher intensity in taking good care of the disabled health and their wellbeing; therefore, the accessibility to health care of the PWMDs who had offspring and spouse as caregivers were significantly higher than the others. A recommendation for further research is to conduct an action research on comprehensive and continuity of PWMDs caring system development in the community.

\section{ACKNOWLEDGEMENT}

I would like to express sincere thanks and appreciation to all persons with movement disability who participated and gave invaluable information for my study. I wish to thank the networks in study areas, and those who participated in my research and those who made my research process flow smoothly and the Research and Training Center for Enhancing Quality of Life of Working-Age People, Khon Kaen University, Khon Kaen, Thailand for academic support.

\section{REFERENCES}

1. National Statistical Office. Ministry of Information and Communication Technology. [Internet]. The 2012 Disability Survey. [cited 2014 Sep 2]. Available from: URL: http://service.nso.go.th/ nso/nso_center/ project/search_center/23project-th.htm . Thai.

2. Ninprapan A. A model for health development of the disabled persons in rural area, Khon Kaen Province. [dissertation]. Graduate School, Khon Kaen University; 2005.146p.Thai.

3. Polkang $B$, Laohasiriwong $W$. [Health service utilization under the Universal Coverage Health Insurance of movement disables in Chaiyaphum Province]. [master's thesis]. Graduate School, Khon Kaen University; 2009. [in Thai].125p.Thai.

4. National Office for Empowerment of Persons with Disabilities. [Internet]. Persons with Disabilities Empowerment Act B.E. 2550. Bangkok, National Office for Empowerment of Persons with Disabilities (NEP); 2007. $24 \mathrm{p}$.

5. Penchansky R, Thomas JW. The concept of access: definition and relationship to consumer satisfaction. Med Care.1981;19(2):127-40.

6. Ministry of Social Development and Human Security. [Internet]. [Report of the registered persons with disabilities data]. [cited 2014 Aug 27]. Available from: URL: http://ecard.nep.go.th/ nep_all/file/ Stat_Dec 54. pdf. Thai.

7. Cohen J. Statistical Power Analysis for the Behavioral Sciences. Routledge; 2013. 689 p.

8. Warwick DP, Lininger CA. The sample survey: Theory and practice. New York, NY, US: McGraw-Hill; 1975. 344 p.

9. Mahoney FI, Barthel DW. FUNCTIONAL EVALUATION: THE BARTHEL INDEX. Maryland State Med J. 1965;14:61-5.

10. Loewen SC, Anderson BA. Predictors of stroke outcome using objective measurement scales. Stroke. 1990;21(1):78-81.

11. Verbrugge LM, Sevak P. Use, Type, and Efficacy of Assistance for Disability. J Gerontol B Psychol Sci Soc Sci. 2002;57(6):S366-79.

12. Agree EM, Freedman VA, Sengupta M. Factors influencing the use of mobility technology in community-based long-term care. J Aging Health. 2004;16(2):267-307.

13. Filmer D. Disability, Poverty, and Schooling in Developing Countries: Results from 14 Household Surveys. World Bank Econ Rev. 2008;22(1):141-63.

14. World Health Organization.[Internet]. World report on disability 2011.[cited 2012 Dec 8]. Available from URL: http://whqlibdoc.who. int/hq/2011/WHO_NMH_VIP_11.01_eng.pdf?ua=1. 